conditions remains unclear. The supposition that reduced postreinforcement pauses by septal Ss reflected enhanced frustrative or aversive reactions to $\mathrm{FR}$ or reinforcing conditions (e.g., withdrawal of sucrose during licking) receives questionable support from their increased responding during dipper-reset times in going from FR-1 to FR-8, since increased concentration of sucrose $(32 \%)$, which enhanced the reward properties of the solution, also served to elevate such responding in both groups. Indeed, pauses that normally develop as FR requirements increase may themselves reflect aversive consequences of the schedule (Ferster \& Skinner, 1957). In any event, it should be recognized that even if an aversive component were isolated as a factor, the knotty question would still remain as to whether enhanced aversive reactivity was primary or secondary to changes in positive incentive-reward functions. The latter still appear to represent major determinants of the observed behavioral alterations following septal lesions.

\section{REFERENCES}

BEATTY, W. W., \& SCHWARTZBAUM, J. S Enhanced reactivity to quinine and saccharin solutions following septal lesions in the rat. Psychonomic Science, 1967, 8, 483-484.

BEATTY, W. W., \& SCHWARTZBAUM, J. S. Consummatory behavior for sucrose following septal lesions in the rat. Joumal of Comparative \& Physiological Psychology, 1968a, 65, 93-102.

BEATTY, W. W., \& SCHWARTZBAUM, J. S. Commonality and specificity of behavioral dysfunctions following septal and hippocampal lesions in rats. Journal of Comparative \& Physiological Psychology, 1968b, 66, 60-68.

CAPLAN, M. The effects of lesions in the septal forebrain or the cingulate cortex on the timing behavior of rats. Unpublished doctoral dissertation, The City University of New York 1968.

FERSTER, C. B., \& SKINNER, B. F. Schedules of reinforcement. New York: Appleton-Century-Crofts, 1957

GREEN, R. H., BEATTY, W. W., \& SCHWARTZBAUM, J. S. Comparative effects of septo-hippocampal and caudate lesions on avoidance behavior in rats. Journal of Comparative \& Physiological Psychology, 1968, 66, 378-388.

HANSING, R. A., SCHWARTZBAUM, J. S., \& THOMPSON, J. B. Operant behavior following unilateral and bilateral caudate lesion in the rat. Journal of Comparative \& Physiological Psychology, 1968, 66, 378-388.

THOMPSON, D. M. Escape from $\mathrm{S}^{D}$ associated with fixed-ratio reinforcement. Journal of the Experimental Analysis of Behavior, 1964, 7, 1-8.

\section{NOTES}

1. Supported by Grant MH 14594-01 from NIMH.

2. Herbert Lehman predoctoral fellow.

3. This animal subsequently deviated to the extent of performing below all control Ss. Since it, therefore, questionably belonged to the same population as the other septal Ss, its subsequent data were excluded from group analysis. In effect, results with shifts in concentration and at high FRs are based on septal Ss that showed enhanced responding at low and medium FRs.

\title{
Ambulatory behavior in the rat as a function of two methods of alcohol administration
}

\section{ZALMAN AMIT and MURIEL H. STERN, McGill University, Montreal, P.Q., Canada}

When alcohol was administered directly into the stomach, ambulation scores of rats in an open-field apparatus were significantly higher than those following alcohol ingested by mouth, and higher following both methods of alcohol administration than after ingestion of water. This suggests that, while the pharmacologic properties of alcohol in general tend to reduce fear in the open-field situation, eliminating the aversive taste of the alcohol increases its fear-reducing effects.

In studies in which alcohol administration serves as an independent variable and a variety of behaviors as dependent variables, it is often assumed that only the volume and concentration of the alcohol solutions ingested are of significance. Recently several studies have suggested that, in addition to the pharmacological properties of alcohol solutions, the mode of alcohol administration is also an important variable affecting behavior. It seems that the mode of administration can either facilitate or inhibit alcohol's pharmacological effects on behavior.

Freed (1968) has reported that I.P. injections of alcohol are aversive and thus have punitive effects on rats in an approach-avoidance situation. A previous study by the present authors (Amit \& Stern, 1969) suggests that administration of alcohol via an intragastric fistula is not aversive, and that rats will work harder to receive intragastric loads of alcohol than they will to obtain alcohol orally in a lever-pressing situation.

The aim of the present study was to determine the effects in rats on open-field ambulatory behavior of two modes of alcohol administration.

\section{METHOD}

The Ss were 12 male hooded rats, 90 days old and weighing approximately $350 \mathrm{~g}$ at the beginning of the experiment. An intragastric fistula was implanted in each $S$ following the method suggested by Kohn (1951) and modified by Amit \& Stern (1969).

On the third day following surgery, using the techniques suggested by Cicero \& Myers (1968), a selection procedure was instituted to establish a low alcohol concentration for six animals for which the concentration established was $13 \%(\mathrm{w})$ and a high alcohol concentration for six animals for which the concentration was $18 \%$ (v). These concentrations remained constant throughout the experiment. Two experimental groups were then selected so that each contained three of the animals on low alcohol concentration and three of the animals on high alcohol concentration. Fourteen days after surgery, all animals were placed on a 22 -h $\mathrm{h}$ water-deprivation schedule.

On Test Day 1 and the 4 subsequent odd-numbered days, each animal in one of the groups received $7 \mathrm{ml}$ of alcohol solution infused directly into the stomach via a variable-speed infusion pump (Harvard Co., Dover, Mass.). On Test Day 2 and the 4 subsequent even-numbered days, the Ss in this group received the same quantity of alcohol by mouth from a Richter tube. The duration of the infusion, $8 \mathrm{~min}$, was equivalent to the mean duration of the oral intake of 22-h water-deprived animals determined in a pilot study. Ten minutes following the administration of alcohol, the animals were placed in the open-field apparatus.

The second group received saline solution (isotonic with the alcohol solutions) by infusion on the odd-numbered days and alcohol solution by infusion on the even-numbered days. All other procedures were the same as those applied to the first group.

The open-field apparatus used in testing 


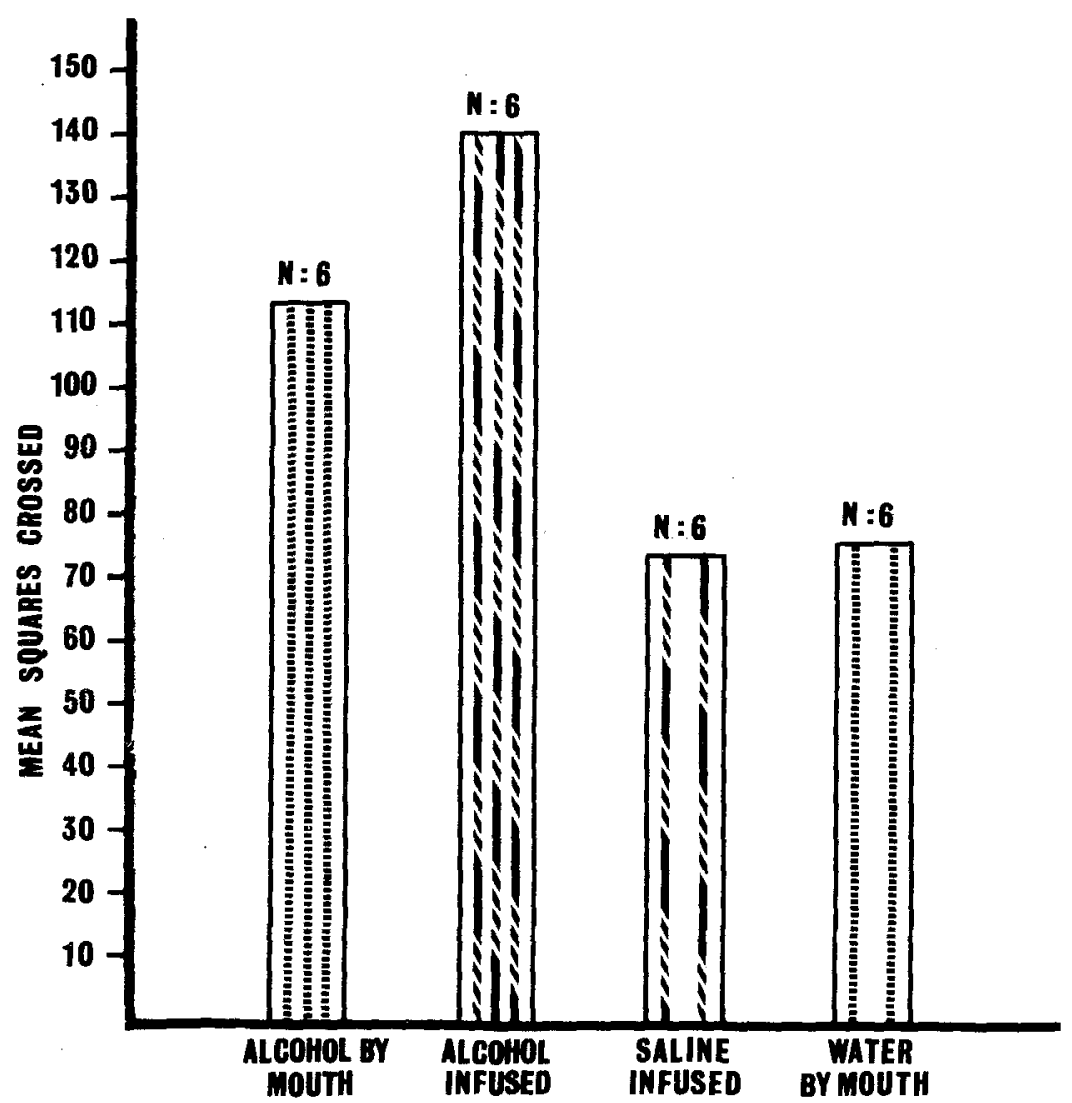

both groups was a $24 \times 24 \times 15$ in. wooden box. The floor of the box was divided into 4-in. black and white squares. All Ss were placed on the center square at the beginning of the session and the number of squares entered by each $S$ was counted during a 7-min test period. A total of 10 testing sessions was held in the open field, five sessions after infusion of alcohol or saline and five after oral intake of alcohol. After completion of testing, water deprivation was discontinued and Ss were allowed ad lib water. Five weeks later, three Ss selected randomly from the first group and three selected randomly from the second group were again placed on a 22-h water-deprivation schedule and then were presented with a Richter tube containing $7 \mathrm{ml}$ of water in the home cage. Following the procedure described above, these six Ss were tested on alternate days in the open field.

\section{RESULTS}

Figure 1 shows the mean number of squares entered by animals under the four conditions of liquid administration. Ss entered the highest number of squares $(\bar{X}=139.6)$ following the infusion of alcohol. This mean is significantly higher $(p<.05)$ than the mean number of squares the Ss entered after ingestion by mouth of the same volume of alcohol $(\overline{\mathrm{X}}=112.2)$. The lowest number of squares entered concentrations.

\section{DISCUSSION}

Fig. 1. Number of squares crossed in the open-field after 4 modes of liquid intake.

infusion of saline. That is, alcohol under both modes of administration tended to raise ambulation above the level obtained with water or saline. This fact is consistent with Arvola's (1960) findings with mice. Intragastric infusion seems, then, to facilitate the effect of alcohol in an open-field situation.

In view of Denenberg's (1963) observation that emotional stress results in a decrease in activity in an open field, we suggest that the higher ambulation scores we observed after alcohol intake were a result of the fear-reducing properties of alcohol. It is possible that the differences in ambulation scores we observed under the two conditions of alcohol administration were due to the aversive taste of the alcohol, which partially inhibits the fear-reducing effects of alcohol. Intragastric infusion, by eliminating the taste of alcohol, appears to facilitate the efficacy of alcohol in reducing fear in rats. This suggestion is in line with our previous finding (Amit \& Stern, 1969) that the aversive taste of alcohol masks positive properties that alcohol might have.

Our data support Freed's (1968) claim occurred after infusion of saline $(\bar{X}=73.2)$. This score and the number of squares entered after ingestion of water by mouth $(\bar{X}=75.4)$ were not significantly different. The number of squares entered after both modes of alcohol administration were significantly higher $(\mathrm{p}<.01)$ than the scores after water and saline ingestion. The scores of the first and the second group after infusion of alcohol were pooled, as these were not significantly different $(p>.10)$. It should be noted that there were no significant behavioral differences attributable to differences in alcohol

The results of this study support an observation made in an earlier study (Amit \& Stern, 1969), that alcohol administered via an intragastric fistula differs in its effects on motor activity from the effects of alcohol taken by mouth. The higher ambulation scores obtained after intragastric infusion of alcohol solutions cannot be attributed to the effect of infusion alone, as infusions of saline isotonic with the alcohol were followed by the lowest ambulation scores and were almost identical with scores observed after ingestion of water by mouth. Moreover, ambulation scores after oral intake of alcohol were significantly higher than the ambulation scores after intragastric that the mode of administration of alcohol may be a crucial variable in determining the effect of alcohol on subsequent behavior. Unlike Freed, however, we found the effects of alcohol to be facilitating and not inhibiting. This appears to be attributable to the difference in mode of administration employed in the two studies. Specifically, intragastric administration of alcohol, which eliminates the aversive taste and smell of the alcohol solutions, appears to facilitate the fear-reducing pharmacological properties of the drug.

\section{REFERENCES}

AMIT, Z., \& STERN, M. H. Alcohol injestion without oropharyngeal sensations. Psychonomic Science, 1969, 15, 162-163.

ARVOLA, A. A method for recording general activity of mice. Acta Physiologica Scandinavica, $1960,49,62-64$.

CICERO, T. J., \& MYERS, R. D. Selection of a single Ethanol test solution in free-choice studies with animals. Quarterly Journal of Studies on Alcohol, 1968, 29, 446-448.

DENENBERG, V. H. Early experience and emotional development. Scientific American, June 1963, 138-146.

FREED, E. X. Effect of self-intoxication upon approach-avoidance conflict in the rat. Quarterly Journal of Studies on Alcohol, 1968, 29, 323-329.

KOHN, M. Satiation of hunger from stomach versus mouth feeding. Journal of Comparative \& Physiological Psychology, 1951, 44, 412-422. 